\title{
Future prospects of Qiliqiangxin on heart failure: epigenetic regulation of regeneration
}

\author{
Lichan Tao, Shutong Shen and Xinli Li* \\ Department of Cardiology, The First Affiliated Hospital of Nanjing Medical University, Nanjing, China \\ ${ }^{*}$ Correspondence: xinli3267_nj@hotmail.com \\ Edited by: \\ Junjie Xiao, Shanghai University, China
}

Keywords: heart failure, epigenetic regulation, regeneration, Qiliqiangxin, prospects

Qiliqiangxin (QL), a traditional Chinese medicine, was approved by China Food and Drug Administration for the treatment of heart failure in 2004 (Li et al., 2013). Our recent multicenter, randomized, double-blind, parallel-group, placebo-controlled study of the effects of QL capsules in patients with chronic heart failure shows that on a background of standard treatment, QL capsules further decreases the levels of plasma $\mathrm{N}$-terminal pro-B-type natriuretic peptide (NTproBNP) during 12 weeks of treatment (Li et al., 2013). However, the underlying mechanism is still unclear.

Recent progress in studying QL on improving exercise tolerance and patients' quality of life highlighted that QL may be through a variety of biological mechanisms to exert its beneficial effects. One possible mechanism may be the regulation of the balance between proinflammatory and anti-inflammatory cytokines in cardiomyocytes (Xiao et al., 2009). In addition, it may down-regulate the cardiac chymase signaling pathway and chymase-mediated AngII production (Zhao et al., 2012). Moreover, it may affect cardiomyocyte death and proliferation, leading to improved cardiac remodeling and cardiac function (Zou et al., 2012).

Traditionally, the adult mammalian heart is regarded as a post-mitotic organ without any regenerative capacity (Rosenzweig, 2012). Accumulating evidence shows that cardiomyocytes in adult mammals actually retain a limited ability to proliferation (Rosenzweig, 2012).
Recently, a study shows that exercise induce physiological hypertrophy featured by cardiomyocyte hypertrophy and proliferation. The cardiomyocyte proliferation is mediated by the reduction of $\mathrm{C} / \mathrm{EBPB}$ and a linked increased of $\mathrm{CBP} / \mathrm{p} 300$ interacting transactivator with ED-rich carboxyterminal domain 4 (CITED4) (Boström et al., 2010). Interestingly, QL has been reported to decrease C/EBP $B$ and also increase CITED4 at 4 weeks after transverse aorta constriction induced cardiac hypertrophy, remodeling and dysfunction in mice (Zou et al., 2012). The changes of C/EBP $\beta$ and CITED4 are paralleled with enhanced proliferation of cardiomyocytes (Zou et al., 2012). Moreover, our recent study also proves that Huangqi (one of the major components of QL) improves cardiac function after acute myocardial infarction in mice by regulating mTORC1 signaling pathway, which also medicates cell proliferation (Wu et al., 2013).

In conclusion, we think QL may mimic a phenotype of physiological hypertrophy and induce heart regeneration, which is beneficial for heart failure.

\section{REFERENCES}

Boström, P., Mann, N., Wu, J., Quintero, P. A., Plovie, E. R., Panáková, D., et al. (2010). C/EBP $\beta$ controls exercise-induced cardiac growth and protects against pathological cardiac remodeling. Cell 143, 1072-1083. doi: 10.1016/j.cell.2010.11.036

Li, X., Zhang, J., Huang, J., Ma, A., Yang, J., Li, W., et al. (2013). A multicenter randomized doubleblind parallel-group placebo-controlled study of the effects of qiliqiangxin capsules in patients with chronic heart failure. J. Am. Coll. Cardiol. 62, 1065-1072. doi: 10.1016/j.jacc.2013.05.035
Rosenzweig, A. (2012). Medicine. Cardiac regeneration. Science 338, 1549-1550. doi: 10.1126/science. 1228951

Wu, X., Cao, Y., Nie, J., Liu, H., Lu, S., Hu, X., et al. (2013). Genetic and pharmacological inhibition of Rheb1-mTORC1 signaling exerts cardioprotection against adverse cardiac remodeling in mice. Am. J. Pathol. 182, 2005-2014. doi: 10.1016/j.ajpath.2013. 02.012

Xiao, H., Song, Y., Li, Y., Liao, Y. H., and Chen, J. (2009). Qiliqiangxin regulates the balance between tumor necrosis factor-alpha and interleukin-10 and improves cardiac function in rats with myocardial function. Cell. Immunol. 260, 51-55. doi: 10.1016/j.cellimm.2009.09.001

Zhao, J., Yang, P., Li, F., Tao, L., Ding, H., Rui, Y., et al. (2012). Therapeutic effects of astragaloside IV on myocardial injuries: multi-target identification and network analysis. PLOS ONE 7:e44938. doi: 10.1371/journal.pone.0044938

Zou, Y., Lin, L., Ye, Y., Wei, J., Zhou, N., Liang, Y., et al. (2012). Qiliqiangxin inhibits the development of cardiac hypertrophy, remodeling, and dysfunction during 4 weeks of pressure overload in mice. J. Cardiovasc. Pharmacol. 59, 268-280. doi: 10.1097/FJC.0b013e31823f888f

Received: 07 October 2013; accepted: 09 October 2013; published online: 24 October 2013.

Citation: Tao L, Shen S and LiX (2013) Future prospects of Qiliqiangxin on heart failure: epigenetic regulation of regeneration. Front. Genet. 4:221. doi: 10.3389/fgene. 2013.00221

This article was submitted to Epigenomics and Epigenetics, a section of the journal Frontiers in Genetics.

Copyright (C) 2013 Tao, Shen and Li. This is an open-access article distributed under the terms of the Creative Commons Attribution License (CC BY). The use, distribution or reproduction in other forums is permitted, provided the original author(s) or licensor are credited and that the original publication in this journal is cited, in accordance with accepted academic practice. No use, distribution or reproduction is permitted which does not comply with these terms. 